Article

\title{
Experimental Effects of Acute Exercise on Iconic Memory, Short-Term Episodic, and Long-Term Episodic Memory
}

\author{
Danielle Yanes and Paul D. Loprinzi * (D) \\ Exercise Psychology Laboratory, Physical Activity Epidemiology Laboratory, Department of Health, \\ Exercise Science and Recreation Management, The University of Mississippi, Oxford, MS 38677, USA; \\ dmyanes@go.olemiss.edu \\ * Correspondence: pdloprin@olemiss.edu; Tel.: +1-662-915-5561; Fax: +1-662-915-5525
}

Received: 24 May 2018; Accepted: 10 June 2018; Published: 11 June 2018

\begin{abstract}
The present experiment evaluated the effects of acute exercise on iconic memory and short- and long-term episodic memory. A two-arm, parallel-group randomized experiment was employed ( $n=20$ per group; $M_{\text {age }}=21$ year). The experimental group engaged in an acute bout of moderate-intensity treadmill exercise for $15 \mathrm{~min}$, while the control group engaged in a seated, time-matched computer task. Afterwards, the participants engaged in a paragraph-level episodic memory task (20 min delay and $24 \mathrm{~h}$ delay recall) as well as an iconic memory task, which involved 10 trials (at various speeds from $100 \mathrm{~ms}$ to $800 \mathrm{~ms}$ ) of recalling letters from a $3 \times 3$ array matrix. For iconic memory, there was a significant main effect for time $\left(F=42.9, p<0.001, \eta^{2} p=0.53\right)$ and a trend towards a group $\times$ time interaction $\left(F=2.90, p=0.09, \eta^{2} p=0.07\right)$, but no main effect for group $\left(\mathrm{F}=0.82, p=0.37, \eta^{2} p=0.02\right)$. The experimental group had higher episodic memory scores at both the baseline (19.22 vs. 17.20) and follow-up (18.15 vs. 15.77), but these results were not statistically significant. These findings provide some suggestive evidence hinting towards an iconic memory and episodic benefit from acute exercise engagement.
\end{abstract}

Keywords: memory consolidation; memory encoding; physical activity; visual memory

\section{Introduction}

Human memory is complex and can be categorized into multiple memory systems including sensory memory (very short term memory recall from various senses such as visual or auditory), working memory (recall of information while concurrently processing other information), prospective memory (remembering to perform a task in the future) and short- and long-term memory [1,2]. With the latter memory systems, declarative memory involves the recall of past events/episodes (episodic memory) or facts (semantic memory), whereas implicit or procedural memory involves memories that are not consciously encoded.

Of interest to the present experiment is sensory memory [3-9] and short- and long-term episodic memory. Visual memory systems can store information for a few hundred milliseconds, which can then be transferred to the limited capacity of the working memory system. Although controversial [10-12], this visual sensory (iconic) memory system is thought to heavily rely on cognitive attention $[13,14]$.

Among the young adult population, most of the research examining the effects of acute exercise on episodic memory function have focused on short-term memory, with little research focusing on longer-term memory [15]. Thus, additional research evaluating the effects of acute exercise on long-term episodic memory function is needed. Research has demonstrated that acute exercise can enhance memory function [16-21], with mechanisms discussed elsewhere [1,22-25]. Briefly, postulated 
mechanisms include, for example, (1) exercise enhancing neuronal excitability; (2) exercise enhancing attentional resource allocation to facilitate memory encoding; (3) exercise upregulating AMPA receptor levels, opening NMDA channels, and increasing EPSP (excitatory post-synaptic potentials) in the hippocampus; (4) exercise priming neurons to be encoded in the memory trace by increasing CREB transcription; (5) BDNF (brain-derived neurotropic factor) expression from exercise; and (6) exercise enhancing dendritic spine growth [1].

In the context of iconic memory, exercise may, in theory, influence memory via exercise-induced changes in attention [16]. Some of the same brain structures (e.g., prefrontal cortex, parietal cortex) subserving attentional focus have been shown to be activated with acute exercise [26-39]. No study, to our knowledge, has examined the effects of acute exercise on iconic memory. Thus, the purpose of this experiment, written as a brief report, was to examine the effects of acute exercise on iconic memory and both short- and long-term episodic memory. We hypothesized that acute exercise would favorably influence both iconic memory as well as short- and long-term episodic memory. We speculated that acute exercise may enhance iconic memory via psychological attentional-based mechanisms, and also hypothesized that, as discussed above, episodic memorial effects from exercise may occur from alterations in key neurotransmitters involved in the consolidation of episodic memories.

\section{Methods}

\subsection{Study Design}

An experimental design was employed. Specifically, a two-arm, parallel-group randomized controlled intervention was utilized. Participants were randomized into either an experimental group or a control group. The experimental group was asked to walk briskly for $15 \mathrm{~min}$ on a treadmill while the control group engaged in a time-matched, seated task that involved playing an online game. Afterwards, the participants commenced the two memory tasks (episodic and iconic). Additional details are provided below. See Supplementary Materials for a schematic of the study design and procedures.

\subsection{Participants}

Each group included 20 participants $(n=40)$. This was based on our previous experimental work on this topic, demonstrating adequate statistical power for other related projects $[16-18,40]$. Recruitment occurred via a convenience-based, non-probability sampling approach. Participants were recruited from the authors' university including both undergraduate and graduate students, ranging in age from 18-35 years. Participants were excluded based on the following criteria:

- $\quad$ Self-reported being a daily smoker [41,42]

- $\quad$ Self-reported being pregnant [43]

- Had exercised within $5 \mathrm{~h}$ of laboratory testing [15]

- Consumed any caffeine within $3 \mathrm{~h}$ of laboratory testing [44]

- $\quad$ Self-reported a concussion or head trauma within the past 30 days [45]

- Self-reported taking marijuana or other illegal drugs within the past 30 days [46]

- Were considered a daily alcohol user (>30 drinks/month for women; $>60$ drinks/month for men) [47]

\subsection{Exercise Protocol}

The treadmill bout of exercise involved walking on a treadmill for 15 min at a self-selected "brisk walking pace". They were instructed to walk at a pace (minimum of $3.0 \mathrm{mph}$ ) as if they were late for catching a bus. This exact exercise protocol has previously been shown to enhance episodic memory performance [40]. The bout of exercise occurred prior to the initial memory assessment. Immediately 
after the bout of exercise, participants rested in a seated position for $5 \mathrm{~min}$. After this resting period, they started the memory assessments, as described below.

\subsection{Control Protocol}

Those randomized to the control group completed a medium-level, online administered, Sudoku puzzle. Participants completed this puzzle for $20 \mathrm{~min}$ prior to completing the memory task (described below). The website for this puzzle is located at https://www.websudoku.com.

\subsection{Memory Assessments and Procedures}

Supplementary Materials present a schematic of the experimental protocol. After the exercise or control conditions, participants read a six-paragraph (374 words) passage used in other episodic memory research [48]. Prior to reading this passage, participants were told to read the passage carefully as, later in the experiment, they would be asked to try and recall as much information from this story as possible. Supplementary Materials also present the details of the scoring rubric that was used for this paragraph-level, episodic memory assessment. The maximum score was 42 , with one point given for each aspect of the story recalled. A higher score indicated greater episodic memory function.

After reading the passage once, participants watched a 5-min video (The Office Bloopers-Season 3) then commenced the iconic memory assessment. During the assessment, participants sat $48 \mathrm{~cm}$ from the display monitor, where their head was stabilized by a chinrest. At this viewing distance, a $3 \times 3$ letter array appeared. Participants completed three practice sessions. Following these practice sessions, and as noted in Supplementary Materials, each whole-report iconic assessment included a " + " symbol $(1000 \mathrm{~ms})$ followed by the display of the $3 \times 3$ letter array. This array was displayed for $100 \mathrm{~ms}, 200 \mathrm{~ms}$, $300 \mathrm{~ms}, 500 \mathrm{~ms}$, or $800 \mathrm{~ms}$ (random order). Two trials for each speed occurred. Thus, 10 iconic trials occurred (two at $100 \mathrm{~ms}$, two at $200 \mathrm{~ms}$, two at $300 \mathrm{~ms}$, two at $500 \mathrm{~ms}$, and two at $800 \mathrm{~ms}$ ). Immediately after each trial, participants were asked to write down as many letters as they could recall, and then write them down in the order in which they appeared in the $3 \times 3$ array. The main outcome for this task (for each interval speed) was the number of correct responses. A response was classified as correct if the participant reported the correct letter in the correct position in the array. Additionally, errors were also calculated. A mislocation error was defined as a reported letter that had been present in the array, but not in the position that was indicated by the participant. An intrusion error was defined as a reported letter that was not present in the array.

After the 10 iconic memory trials, participants watched another 5-min video (The Office Bloopers-Season 4). Following this video, and for the short-term episodic memory assessment (20-min delay), they were asked to recall as much information as possible from the six-paragraph passage (Supplementary Materials). Participants wrote down as much information from this passage as they could remember. This concluded the first laboratory assessment. For the long-term episodic memory assessment, participants returned to the laboratory approximately $24 \mathrm{~h}$ (range, 22-26 h) after their first laboratory visit. Upon arrival, they sat for 5-min and then re-completed the episodic memory assessment by writing down as much information from the story that they could remember.

\subsection{Additional Assessments}

Various other assessments were completed (at the beginning of the visit) to ensure that the two groups were similar in these parameters. As a measure of habitual physical activity behavior, and reported as time spent per week in moderate-to-vigorous physical activity (MVPA), participants completed a survey (Physical Activity Vital Signs Questionnaire) [49]. Waist circumference was measured to provide anthropometric characteristics of the sample. Finally, before, during, and after the exercise and control conditions, heart rate (chest-strapped Polar monitor, F1 model) was assessed. 


\subsection{Statistical Analysis}

All statistical analyses were computed in SPSS (v. 24). For the iconic memory assessment, a 2 (group) $\times 10$ (trials) repeated measures ANOVA was computed. For the episodic memory assessment, a 2 (group) $\times 2$ (time) repeated measures ANOVA was computed. Statistical significance was set at an alpha of 0.05 . Partial eta-squared $\left(\eta^{2} p\right)$ was calculated as a measure of effect size.

\section{Results}

Table 1 displays the characteristics of the sample. Across both groups, participants were similar regarding age, gender, race, waist circumference, and engagement in habitual exercise. Resting heart rates were similar across the two groups, and as expected, heart rate increased substantively during exercise (from 74 to $127 \mathrm{bpm}$ ).

Table 1. Characteristics of the study variables.

\begin{tabular}{lcc}
\hline \multicolumn{1}{c}{ Variable } & Exercise $(\boldsymbol{n}=\mathbf{2 0})$ & Control $(\boldsymbol{n}=\mathbf{2 0})$ \\
\hline Age, mean years & $21.0(1.0)$ & $20.8(0.9)$ \\
\% Female & 75.0 & 55.0 \\
\% white & 85.0 & 65.0 \\
Waist circumference, mean cm & $87.6(13.6)$ & $84.2(9.6)$ \\
MVPA, mean min/week & $198.0(155.2)$ & $224.1(193.4)$ \\
\hline Heart Rate, mean & & \\
$\quad$ Resting & $73.8(12.5)$ & $68.2(12.3)$ \\
Midpoint & $124.9(22.7)$ & - \\
$\quad$ Endpoint & $126.8(23.6)$ & - \\
$\quad$ Post & $84.2(15.9)$ & $68.9(11.8)$ \\
\hline Speed, mean mph & $3.6(0.1)$ & - \\
\hline
\end{tabular}

MVPA, Moderate to vigorous physical activity. Values in parentheses are SD estimates.

Table 2 displays the iconic and episodic memory scores for both groups. For iconic memory, and for absolute correct, there was a significant main effect for time $\left(\mathrm{F}=42.9, p<0.001, \eta^{2}{ }_{p}=0.53\right)$ and a trend toward a linear group-time interaction ( $\left.F=2.90, p=0.09, \eta^{2} p=0.07\right)$, but no main effect for group $\left(\mathrm{F}=0.82, p=0.37, \eta^{2} p=0.02\right)$. Figure 1 displays the mean absolute correct scores for both groups. For most iconic trials, the exercise group (vs. control group) had a higher absolute correct score. For the mislocation iconic error assessment, there was no significant main effect for time $(\mathrm{F}=1.56$, $\left.p=0.12, \eta^{2} p=0.04\right)$ or a significant group-time interaction $\left(\mathrm{F}=0.97, p=0.46, \eta^{2} p=0.02\right)$. Similarly, for intrusion errors, there was no significant main effect for time $\left(\mathrm{F}=1.20, p=0.29, \eta^{2} p=0.03\right)$ or a significant group-time interaction $\left(\mathrm{F}=0.74, p=0.66, \eta^{2} p=0.01\right)$. Table 2 also displays the episodic memory results. The experimental group had higher episodic memory scores at both the baseline (19.22 vs. 17.20) and follow-up (18.15 vs. 15.77). There was a significant main effect for time ( $\mathrm{F}=13.70$, $\left.p=0.001, \eta^{2} p=0.27\right)$, but there was no significant group-time interaction $\left(\mathrm{F}=0.27, p=0.60, \eta^{2} p=0.01\right)$ or main effect for group $\left(\mathrm{F}=1.00, p=0.32, \eta^{2} p=0.03\right.$ ) (Figure 2).

Table 2. Memory scores (iconic memory, mean) across the experimental and control groups.

\begin{tabular}{lcccc}
\hline \multirow{2}{*}{ Variable } & \multicolumn{2}{c}{ Exercise $(\boldsymbol{n}=\mathbf{2 0})$} & \multicolumn{2}{c}{ Control $(\boldsymbol{n}=\mathbf{2 0})$} \\
\cline { 2 - 5 } & Trial 1 & Trial 2 & Trial 1 & Trial 2 \\
\hline Iconic memory, mean & & & & \\
100 ms & & & & \\
$\quad$ Number correct & $1.95(1.3)$ & $2.70(0.9)$ & $2.10(1.0)$ & $2.55(0.8)$ \\
$\quad$ Number of mislocation errors & $0.45(0.6)$ & $0.45(0.6)$ & $0.25(0.5)$ & $0.60(1.0)$ \\
$\quad$ Number of intrusion errors & $0.65(1.3)$ & $0.35(0.8)$ & $0.20(0.5)$ & $0.10(0.3)$ \\
\hline 200 ms & & & & \\
$\quad$ Number correct & $3.05(1.0)$ & $3.15(1.0)$ & $3.10(0.7)$ & $2.95(0.8)$ \\
$\quad$ Number of mislocation errors & $0.85(0.9)$ & $0.45(0.7)$ & $0.45(0.6)$ & $0.45(0.7)$ \\
$\quad$ Number of intrusion errors & $0.25(0.7)$ & $0.35(0.7)$ & $0.10(0.3)$ & $0.25(0.6)$ \\
\hline
\end{tabular}


Table 2. Cont.

\begin{tabular}{|c|c|c|c|c|}
\hline \multirow{2}{*}{ Variable } & \multicolumn{2}{|c|}{ Exercise $(n=20)$} & \multicolumn{2}{|c|}{ Control $(n=20)$} \\
\hline & Trial 1 & Trial 2 & Trial 1 & Trial 2 \\
\hline \multicolumn{5}{|l|}{$300 \mathrm{~ms}$} \\
\hline Number correct & $3.80(1.1)$ & $3.55(1.0)$ & $3.25(0.9)$ & $3.40(0.9)$ \\
\hline Number of mislocation errors & $0.40(0.9)$ & $0.70(0.9)$ & $0.50(0.8)$ & $0.60(1.0)$ \\
\hline Number of intrusion errors & $0.35(0.9)$ & $0.40(0.8)$ & $0.30(0.5)$ & $0.25(0.44)$ \\
\hline \multicolumn{5}{|l|}{$500 \mathrm{~ms}$} \\
\hline Number correct & $4.90(1.4)$ & $4.90(1.2)$ & $4.40(1.2)$ & $4.50(1.4)$ \\
\hline Number of mislocation errors & $0.40(0.8)$ & $0.85(1.1)$ & $0.30(0.7)$ & $0.20(0.5)$ \\
\hline Number of intrusion errors & $0.45(0.9)$ & $0.25(0.5)$ & $0.30(0.7)$ & $0.10(0.3)$ \\
\hline \multicolumn{5}{|l|}{$800 \mathrm{~ms}$} \\
\hline Number correct & $4.10(1.3)$ & $5.80(1.3)$ & $4.35(1.4)$ & $5.85(1.0)$ \\
\hline Number of mislocation errors & $1.05(1.6)$ & $0.55(1.0)$ & $0.65(1.0)$ & $0.10(0.4)$ \\
\hline Number of intrusion errors & $0.30(0.5)$ & $0.50(0.8)$ & $0.40(0.8)$ & $0.30(0.8)$ \\
\hline \multicolumn{5}{|l|}{ Episodic memory, mean } \\
\hline Short-term & \multicolumn{2}{|c|}{$19.22(6.7)$} & \multicolumn{2}{|c|}{$17.20(7.9)$} \\
\hline Long-term & \multicolumn{2}{|c|}{$18.15(6.2)$} & \multicolumn{2}{|c|}{$15.77(7.3)$} \\
\hline
\end{tabular}

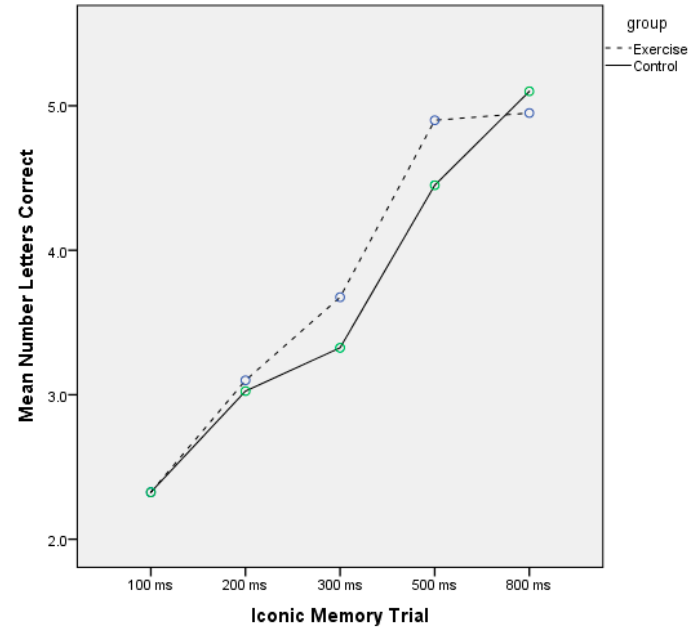

Figure 1. Iconic memory performance (absolute correct) across the experimental and control groups. Scores are the averages for each of the two trials for each temporal period. Results are presented from the shortest $(100 \mathrm{~ms})$ to longest $(800 \mathrm{~ms})$ iconic trials (in the experiment, trials were counterbalanced).

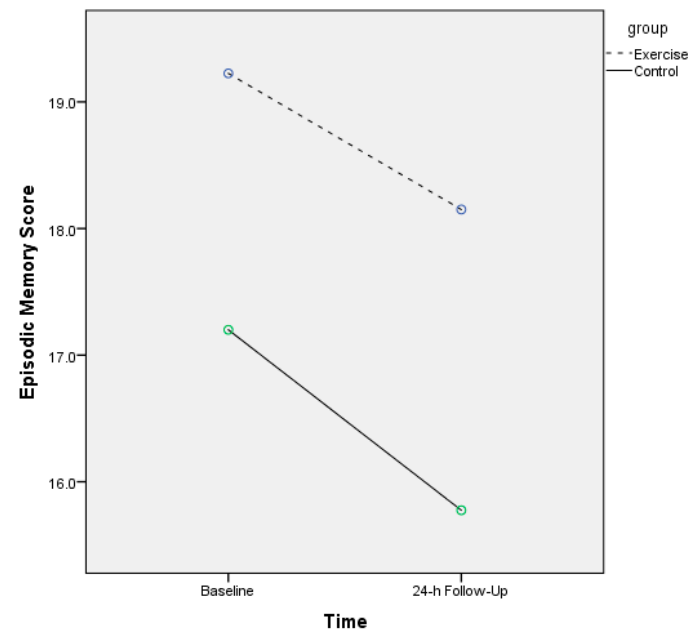

Figure 2. Episodic memory function scores across the experimental and control groups. 


\section{Discussion}

Memory function is critical for optimal daily functioning. The potential enhancement of memory function from exercise has numerous clinical implications for various populations including healthy adults and those with neurological conditions such as Alzheimer's disease and Parkinson's disease [50-52]. Among these populations, the enhancement of memory may help to facilitate future exercise behavior and help to attenuate the decline in memory function $[53,54]$.

Extending this emerging exercise neurobiology field, the present experiment evaluated whether acute moderate-intensity exercise was associated with iconic and episodic memory function. Our results provided suggestive evidence that acute moderate-intensity exercise was associated with better iconic and episodic memory function including both short- and long-term memory. Notably, however, although the exercise group had better mean iconic and episodic memory scores when compared to the control group, these aggregate differences did not reach statistical significance. Our relatively small sample size may have contributed to statistical power issues. However, numerous other related experiments on exercise and memory have been adequately powered with the same sample size employed in our experiment [16-18,40]. Of course, relying strictly on statistical significance is a major research concern $[55,56]$.

Given the novelty of this exercise and iconic memory paradigm, it would be of interest for future work to continue to evaluate this model. Of particular interest would be to evaluate whether an intensity-specific effect is observable [57], particularly for iconic memory. Perhaps moderate-intensity walking was not sufficient to induce an optimal level of arousal, and in turn, psychological attention. Of course, it is likely that too high of an intensity, with too short of a recovery period, may have the opposite effect by inducing psychological fatigue, and in turn, impairing iconic memory. Unlike the present study, other work on this topic may wish to standardize the intensity of the exercise bout to minimize between-subject differences in the exercise stimulus. Further work on this topic should also carefully consider the control task. Our control participants engaged in a Sudoku puzzle which, in theory, could have primed their performance on our evaluated memory tasks, and in turn, possibly masked any potential differences between the groups.

Although the present experiment is the first to our knowledge to evaluate the effects of acute exercise on iconic memory, this study extends other related work that has evaluated the effects of acute exercise on spatial-based memory, which includes a visual component like the present iconic memory task. In fact, meta-analytic research demonstrates that memory sub-type may moderate the effects of acute exercise on memory, and acute exercise is more strongly associated with short-term visuo-spatial memory when compared to verbal-auditory memory [19]. Our present episodic memory findings, although not statistically significant, converge with other work, suggesting that acute exercise may be associated with both short- and long-term episodic memory $[15,18]$.

In conclusion, the present study evaluated the experimental effects of acute moderate-intensity aerobic exercise on iconic memory, short-term episodic, and long-term episodic memory. Our findings provide some suggestive evidence hinting towards an iconic memory and episodic benefit from acute exercise engagement. Future confirmatory work, particularly for iconic memory, is warranted. Future work on this topic should also aim to determine what magnitude of change in these memory parameters is clinically meaningful.

Supplementary Materials: Available online at http:/ / www.mdpi.com/2077-0383/7/6/146/s1. Supplementary Materials A. Schematic of the experimental protocol; Supplementary Materials B. Episodic Memory Passage; Supplementary Materials C. Scoring units for episodic memory passage.

Author Contributions: D.Y. collected the data. P.D.L. conceptualized the manuscript and drafted the manuscript.

Funding: This research received no external funding.

Conflicts of Interest: The authors declare no conflict of interest. 


\section{References}

1. Loprinzi, P.D.; Edwards, M.K.; Frith, E. Potential avenues for exercise to activate episodic memory-related pathways: A narrative review. Eur. J. Neurosci. 2017, 46, 2067-2077. [CrossRef] [PubMed]

2. Loprinzi, P.D.; Frith, E.; Edwards, M.K.; Sng, E.; Ashpole, N. The effects of exercise on memory function among young to middle-aged adults: Systematic review and recommendations for future research. Am. J. Health Promot. 2018, 32, 691-704. [CrossRef] [PubMed]

3. Bradley, C.; Pearson, J. The sensory components of high-capacity iconic memory and visual working memory. Front. Psychol. 2012, 3, 355. [CrossRef] [PubMed]

4. Thomas, L.E.; Irwin, D.E. Voluntary eyeblinks disrupt iconic memory. Percept. Psychophys. 2006, 68, 475-488. [CrossRef] [PubMed]

5. Ogmen, H.; Herzog, M.H. A new conceptualization of human visual sensory-memory. Front. Psychol. 2016, 7, 830. [CrossRef] [PubMed]

6. Arning, L.; Stock, A.K.; Kloster, E.; Epplen, J.T.; Beste, C. NPY2-receptor variation modulates iconic memory processes. Eur. Neuropsychopharmacol. 2014, 24, 1298-1302. [CrossRef] [PubMed]

7. Gegenfurtner, K.R.; Sperling, G. Information transfer in iconic memory experiments. J. Exp. Psychol. Hum. Percept. Perform. 1993, 19, 845-866. [CrossRef] [PubMed]

8. Sperling, G. Why we need iconic memory. Behav. Brain Sci. 1983, 6, 37-39. [CrossRef]

9. Sperling, G. The information available in brief visual presentations. Psychol. Monogr. 1960, 74, 1-29. [CrossRef]

10. Aru, J.; Bachmann, T. Expectation creates something out of nothing: The role of attention in iconic memory reconsidered. Conscious Cogn. 2017, 53, 203-210. [CrossRef] [PubMed]

11. Mack, A.; Erol, M.; Clarke, J. When expectation confounds iconic memory: A reply to Bachmann and Aru (2016). Conscious Cogn. 2017, 49, 363-364. [CrossRef] [PubMed]

12. Bachmann, T.; Aru, J. When expectation confounds iconic memory. Conscious Cogn. 2016, 45, $198-199$. [CrossRef] [PubMed]

13. Persuh, M.; Genzer, B.; Melara, R.D. Iconic memory requires attention. Front. Hum. Neurosci. 2012, 6, 126. [CrossRef] [PubMed]

14. Mack, A.; Erol, M.; Clarke, J.; Bert, J. No iconic memory without attention. Conscious Cogn. 2016, 40, 1-8. [CrossRef] [PubMed]

15. Labban, J.D.; Etnier, J.L. Effects of acute exercise on long-term memory. Res. Q. Exerc. Sport 2011, 82, 712-721. [CrossRef] [PubMed]

16. Loprinzi, P.D.; Kane, C.J. Exercise and cognitive function: A randomized controlled trial examining acute exercise and free-living physical activity and sedentary effects. Mayo Clin. Proc. 2015, 90, 450-460. [CrossRef] [PubMed]

17. Crush, E.A.; Loprinzi, P.D. Dose-response effects of exercise duration and recovery on cognitive functioning. Percept. Mot. Skills 2017, 124, 1164-1193. [CrossRef] [PubMed]

18. Frith, E.; Sng, E.; Loprinzi, P.D. Randomized controlled trial evaluating the temporal effects of high-intensity exercise on learning, short-term and long-term memory, and prospective memory. Eur. J. Neurosci. 2017, 46, 2557-2564. [CrossRef] [PubMed]

19. Roig, M.; Nordbrandt, S.; Geertsen, S.S.; Nielsen, J.B. The effects of cardiovascular exercise on human memory: A review with meta-analysis. Neurosci. Biobehav. Rev. 2013, 37, 1645-1666. [CrossRef] [PubMed]

20. Roig, M.; Thomas, R.; Mang, C.S.; Snow, N.J.; Ostadan, F.; Boyd, L.A.; Lundbye-Jensen, J. Time-dependent effects of cardiovascular exercise on memory. Exerc. Sport Sci. Rev. 2016, 44, 81-88. [CrossRef] [PubMed]

21. Chang, Y.K.; Labban, J.D.; Gapin, J.I.; Etnier, J.L. The effects of acute exercise on cognitive performance: A meta-analysis. Brain Res. 2012, 1453, 87-101. [CrossRef] [PubMed]

22. McMorris, T. Developing the catecholamines hypothesis for the acute exercise-cognition interaction in humans: Lessons from animal studies. Physiol. Behav. 2016, 165, 291-299. [CrossRef] [PubMed]

23. McMorris, T.; Turner, A.; Hale, B.J.; Sproule, J. Beyond the catecholamines hypothesis for an acute exercise-cognition interaction: A neurochemical perspective. In Exercise-Cognition Interaction: Neuroscience Perspectives; McMorris, T., Ed.; Academic Press: Cambridge, MA, USA, 2016; pp. 65-103. 
24. McMorris, T.; Sproule, J.; Turner, A.; Hale, B.J. Acute, intermediate intensity exercise, and speed and accuracy in working memory tasks: A meta-analytical comparison of effects. Physiol. Behav. 2011, 102, 421-428. [CrossRef] [PubMed]

25. Loprinzi, P.D.; Frith, E. A brief primer on the mediational role of BDNF in the exercise-memory link. Clin. Physiol. Funct. Imaging 2018. [CrossRef] [PubMed]

26. Alves, C.R.; Tessaro, V.H.; Teixeira, L.A.; Murakava, K.; Roschel, H.; Gualano, B.; Takito, M.Y. Influence of acute high-intensity aerobic interval exercise bout on selective attention and short-term memory tasks. Percept. Mot. Skills 2014, 118, 63-72. [CrossRef] [PubMed]

27. McMorris, T.; Davranche, K.; Jones, G.; Hall, B.; Corbett, J.; Minter, C. Acute incremental exercise, performance of a central executive task, and sympathoadrenal system and hypothalamic-pituitary-adrenal axis activity. Int. J. Psychophysiol. 2009, 73, 334-340. [CrossRef] [PubMed]

28. Geva, R.; Zivan, M.; Warsha, A.; Olchik, D. Alerting, orienting or executive attention networks: Differential patters of pupil dilations. Front. Behav. Neurosci. 2013, 7, 145. [CrossRef] [PubMed]

29. Fingelkurts, A.A.; Fingelkurts, A.A. Attentional state: From automatic detection to willful focused concentration. In Attention and Meaning. The Attentional Basis of Meaning; Marchetti, G., Benedetti, G., Alharbi, A., Eds.; Nova Science Publishers: Hauppauge, NY, USA, 2015; pp. 133-150.

30. Kinomura, S.; Larsson, J.; Gulyas, B.; Roland, P.E. Activation by attention of the human reticular formation and thalamic intralaminar nuclei. Science 1996, 271, 512-515. [CrossRef] [PubMed]

31. Sarter, M.; Gehring, W.J.; Kozak, R. More attention must be paid: The neurobiology of attentional effort. Brain Res. Rev. 2006, 51, 145-160. [CrossRef] [PubMed]

32. Iwamoto, G.A.; Kaufman, M.P. Caudal ventrolateral medullary cells responsive to muscular contraction. J. Appl. Physiol. 1987, 62, 149-157. [CrossRef] [PubMed]

33. Dietrich, A.; Audiffren, M. The reticular-activating hypofrontality (RAH) model of acute exercise. Neurosci. Biobehav. Rev. 2011, 35, 1305-1325. [CrossRef] [PubMed]

34. Rajab, A.S.; Crane, D.E.; Middleton, L.E.; Robertson, A.D.; Hampson, M.; MacIntosh, B.J. A single session of exercise increases connectivity in sensorimotor-related brain networks: A resting-state fMRI study in young healthy adults. Front. Hum. Neurosci. 2014, 8, 625. [CrossRef] [PubMed]

35. Wang, Z.; Myers, K.G.; Guo, Y.; Ocampo, M.A.; Pang, R.D.; Jakowec, M.W.; Holschneider, D.P. Functional reorganization of motor and limbic circuits after exercise training in a rat model of bilateral parkinsonism. PLoS ONE 2013, 8, e80058. [CrossRef] [PubMed]

36. Dehaene, S.; Kerszberg, M.; Changeux, J.P. A neuronal model of a global workspace in effortful cognitive tasks. Proc. Natl. Acad. Sci. USA 1998, 95, 14529-14534. [CrossRef] [PubMed]

37. Daffner, K.R.; Scinto, L.F.; Weitzman, A.M.; Faust, R.; Rentz, D.M.; Budson, A.E.; Holcomb, P.J. Frontal and parietal components of a cerebral network mediating voluntary attention to novel events. J. Cogn. Neurosci. 2003, 15, 294-313. [CrossRef] [PubMed]

38. Enders, H.; Cortese, F.; Maurer, C.; Baltich, J.; Protzner, A.B.; Nigg, B.M. Changes in cortical activity measured with EEG during a high-intensity cycling exercise. J. Neurophysiol. 2016, 115, 379-388. [CrossRef] [PubMed]

39. Tsujii, T.; Komatsu, K.; Sakatani, K. Acute effects of physical exercise on prefrontal cortex activity in older adults: A functional near-infrared spectroscopy study. Adv. Exp. Med. Biol. 2013, 765, 293-298. [PubMed]

40. Sng, E.; Frith, E.; Loprinzi, P.D. Temporal effects of acute walking exercise on learning and memory function. Am. J. Health Promot. 2017. [CrossRef] [PubMed]

41. Jubelt, L.E.; Barr, R.S.; Goff, D.C.; Logvinenko, T.; Weiss, A.P.; Evins, A.E. Effects of transdermal nicotine on episodic memory in non-smokers with and without schizophrenia. Psychopharmacology 2008, 199, 89-98. [CrossRef] [PubMed]

42. Klaming, R.; Annese, J.; Veltman, D.J.; Comijs, H.C. Episodic memory function is affected by lifestyle factors: A 14-year follow-up study in an elderly population. Neuropsychol. Dev. Cogn. B Aging Neuropsychol. Cogn. 2017, 24, 528-542. [CrossRef] [PubMed]

43. Henry, J.D.; Rendell, P.G. A review of the impact of pregnancy on memory function. J. Clin. Exp. Neuropsychol. 2007, 29, 793-803. [CrossRef] [PubMed]

44. Sherman, S.M.; Buckley, T.P.; Baena, E.; Ryan, L. Caffeine enhances memory performance in young adults during their non-optimal time of day. Front. Psychol. 2016, 7, 1764. [CrossRef] [PubMed]

45. Wammes, J.D.; Good, T.J.; Fernandes, M.A. Autobiographical and episodic memory deficits in mild traumatic brain injury. Brain Cogn. 2017, 111, 112-126. [CrossRef] [PubMed] 
46. Hindocha, C.; Freeman, T.P.; Xia, J.X.; Shaban, N.D.C.; Curran, H.V. Acute memory and psychotomimetic effects of cannabis and tobacco both 'joint' and individually: A placebo-controlled trial. Psychol. Med. 2017, 47, 2708-2719. [CrossRef] [PubMed]

47. Le Berre, A.P.; Fama, R.; Sullivan, E.V. Executive functions, memory, and social cognitive deficits and recovery in chronic alcoholism: A critical review to inform future research. Alcohol. Clin. Exp. Res. 2017, 41, 1432-1443. [CrossRef] [PubMed]

48. Prichard, E.C.; Christman, S.D. Inconsistent-handed advantage in episodic memory extends to paragraph-level materials. Memory 2017, 25, 1063-1071. [CrossRef] [PubMed]

49. Ball, T.J.; Joy, E.A.; Gren, L.H.; Shaw, J.M. Concurrent validity of a self-reported physical activity "vital sign" questionnaire with adult primary care patients. Prev. Chronic Dis. 2016, 13, E16. [CrossRef] [PubMed]

50. Loprinzi, P.D.; Frith, E.; Ponce, P. Memorcise and Alzheimer's disease. Phys. Sportsmed. 2018, 46, $145-154$. [CrossRef] [PubMed]

51. Loprinzi, P.D.; Sng, E.; Frith, E. 'Memorcise': Implications for patient compliance and medication adherence. Phys. Sportsmed. 2018, 46, 21-23. [CrossRef] [PubMed]

52. Loprinzi, P.D.; Frith, E. Memorcise in the context of Parkinson's disease. J. Cogn. Enhanc. 2018. [CrossRef]

53. Loprinzi, P.D.; Herod, S.M.; Cardinal, B.J.; Noakes, T.D. Physical activity and the brain: A review of this dynamic, bi-directional relationship. Brain Res. 2013, 1539, 95-104. [CrossRef] [PubMed]

54. Ponce, P.; Loprinzi, P.D. A bi-directional model of exercise and episodic memory function. Med. Hypotheses 2018, 117, 3-6. [CrossRef]

55. Lash, T.L. The harm done to reproducibility by the culture of null hypothesis significance testing. Am. J. Epidemiol. 2017, 186, 627-635. [CrossRef] [PubMed]

56. McShane, B.B.; Gal, D.; Gelman, A.; Robert, C.; Tackett, J.L. Abandon Statistical Significance. Available online: https:/ / arxiv.org/abs/1709.07588 (accessed on 24 May 2018).

57. Hutchinson, J.C.; Tenenbaum, G. Attention focus during physical effort: The mediating role of task intensity. Psychol. Sport Exerc. 2007, 8, 233-245. [CrossRef]

(C) 2018 by the authors. Licensee MDPI, Basel, Switzerland. This article is an open access article distributed under the terms and conditions of the Creative Commons Attribution (CC BY) license (http:/ / creativecommons.org/licenses/by/4.0/). 